\title{
Improvement of Project Control Management in a Chemical Plant
}

\author{
K. Nutsiri \& P. Chutima \\ Faculty of Engineering/Industrial Engineering \\ Chulalongkorn University, Wangmai, Patumwan, Bangkok 10330, Thailand
}

\begin{abstract}
The objective of the research is to improve project controlling in a chemical plant to projects completed on time delivery through the adaptation of the project control technique from Project Management Body of Knowledge (PMBOK) to improve project on time delivery, cost and quality. The technique involves the management of project time, cost, quality and risk to provide a higher level of project performance. The result shows that the percentage of projects completed on time increases from $41 \%$ in 2013 to $90 \%$ with acceptable cost in 2014.
\end{abstract}

KEYWORD: Project Control; Plant Capacity Increase

\section{INSTRUCTION}

\subsection{Research background}

The case study is a chemical plant producing surfactant which is a joint venture with one of the biggest petrochemical plants in Thailand. The company has to increase production capacity to support expected substantial sales growth in 2016; therefore several sub-projects are developed for 2012-2015. Historical data indicated that the number of projects completed on time was very low, i.e. $35 \%$ in 2012 and $41 \%$ in 2013 (Table 1). The company needs to improve the number of projects on-time delivery in 2014 so that the capacity improvement plan in 2015 can be achieved successfully.

Table 1 Number of project completed on time.

\begin{tabular}{|c|c|c|c|c|c|}
\hline Item & Year & Pjt. Q'ty & On Time & Delay & Delay\% \\
\hline 1 & 2012 & 37 & 24 & 13 & $35 \%$ \\
\hline 2 & 2013 & 22 & 13 & 9 & $41 \%$ \\
\hline
\end{tabular}

The guideline on project time management within Project Management Body of Knowledge (PMBOK) is employed as a basis to establish the appropriate plan in this work. It involves defining activities, sequencing activities, estimating activity resources, estimating activities durations, develop schedule and control schedule. Mudau and Pretorius (2009) provided the project control and project risk management models for ensuring project success. They identified factors that contribute to project success in the South African oil and gas company.
The project control and risk model were tested in a project execution environment. It was found that the model depended on two variables namely project management success and project product success.

Jia (2010) mentioned that project management is unique and not similar to other projects. The technique can be adapted to any project depending on how much project controller understands the project requirements in defining the project activities and sequencing activities. After that it will be simple to estimate the cost, budget, resources, material and manpower, time period required to complete each activity. The techniques that each project controller used may vary but they all aim to not overestimate the budget and not cause delays to the project.

Kažovi and Valeni (2013) reported on the complexity of project management in NonGovernment Organizations. They used the Microsoft project program to help establish the task and monitoring, budget spending, and project dead line.

Rattanaguagungwan (2013) Project is a temporary process with an explicit starting and closing period to provide project outcome to meet project objective(s) and goal within cost limitations, resources and time. The project work breakdown structure (WBS) is used for defining the work area and activity, sequencing the project activity and use the activity after sequencing to input the resource to each activity, the resource must be difference source in each activity or same source only for other period of working time. 


\section{RESEARCH METHODOLOGY}

\subsection{Project time management}

To improve on-time delivery of the project, project engineer or project manager has to follow the following steps.

Step 1: Define the activities to identify the specific action to be performed to produce the project deliverables.

Step 2: Sequence activities to identify and document relationship between the project activities.

Step 3: Calculate activity resources for estimating the material type and quantity, human resource, and equipment or supplier required for each activity.

Step 4: Estimate activity duration to approximate the number of work periods required to complete individual activities with estimated resources.

Step 5: Develop schedule to analyze activity sequences, durations, resource requirement and schedule constraints to create the project schedule from starting date to project completion.

Step 6: Control schedule to monitor the status of project to update progress and manage the change of the schedule base line.

The review of project progress report is necessary to show the performance of each activity and the modification of schedule base on the change request to prevent project delay.

\subsection{Project cost management}

The project cost and budget estimating to complete within approved budget can be done as follows.

Step 1: Estimation costs to develop an approximation of the monetary resource for material, human resource, equipment and supplier required in each activity.

Step 2: Determine budget to combine the estimated costs of individual activities or work package to establish an authorized cost base line.

Step 3: Control costs by monitoring the status of project spending and compare with project progressive the change management to be control by authorized person to prevent cost spending over approved budget.

\subsection{Project quality management}

The project quality management to meet with project requirement and specification can be done as follows.

Step 1: Plan quality to identifying quality requirements and standard to project.

Step 2: Perform quality assurance to audit the quality requirement and result from quality control measurement to ensure appropriate quality standard.

Step 3: Perform quality control to monitoring and recording of executing the quality activities to access performance and recommend necessary changes.

\subsection{Project risk management}

The project risk management to identify probability of event to impact to project completion to manage the risk to be process as follows:

Step 1: plan risk management to define how to conduct risk management activities for the project, planning is important to provide sufficient resource and time for risk management activities

Step 2: identify risks to determining which risk may affect the project and documenting their characteristics.

Step 3: Perform qualitative risk analysis to prioritizing risks for future analysis or action by assessing and combining their relative probability or likelihood of occurrence and impact, the project team shall be identify risk level and reduce influence of bias.

Step 4: Perform quantitative risk analysis is the process of numerically analyzing the effect of identified risks on overall project objectives

Step 5: Plan risk responses to creating option and actions to enhance opportunities and to reduce threats to project objective, plan risk responses addresses the risks by their priorities inserting resources and activities into project budget, schedule and project management plan as needed.

Step 6: Monitor and control risk to tracking each critical activity and measuring the risk process effectiveness throughout the project

\section{RESULTS}

Having followed all steps recommended in PMBOK, the results are as follows.

\subsection{Project time management}

To define the project activity based on construction project for main task of engineering design, fabrication, installation, testing and commissioning process and separate to sub-activity of each project for estimating budget, resource and time duration.

The project schedule of the study company is developed using the Microsoft Project program with information related to all project activities, estimated working period and duration, and precedence relationship of activities as shown in Figure 1. 


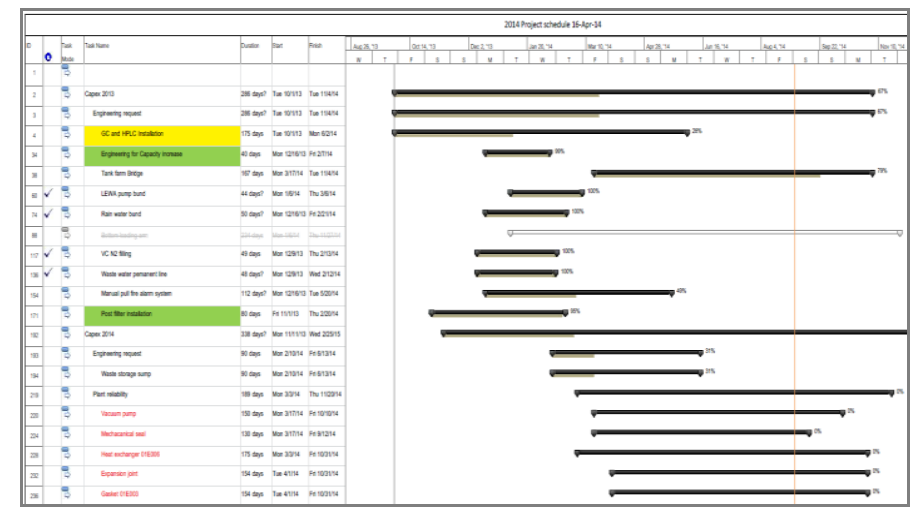

Figure 1: Project schedule

The Microsoft Project program helps manage project time and schedule for multiple projects and establish project milestones to compare actual progress against plan. It can be used to evaluate if the project is on schedule or not. In case of delay, the project engineer or project manager can chase the schedule or postpone activity with the approval of the project team members

\subsection{Project cost management}

To develop an approximation of the monetary resources required for each activity and/or work area of project the estimation document is provided as shown in Figure 2.

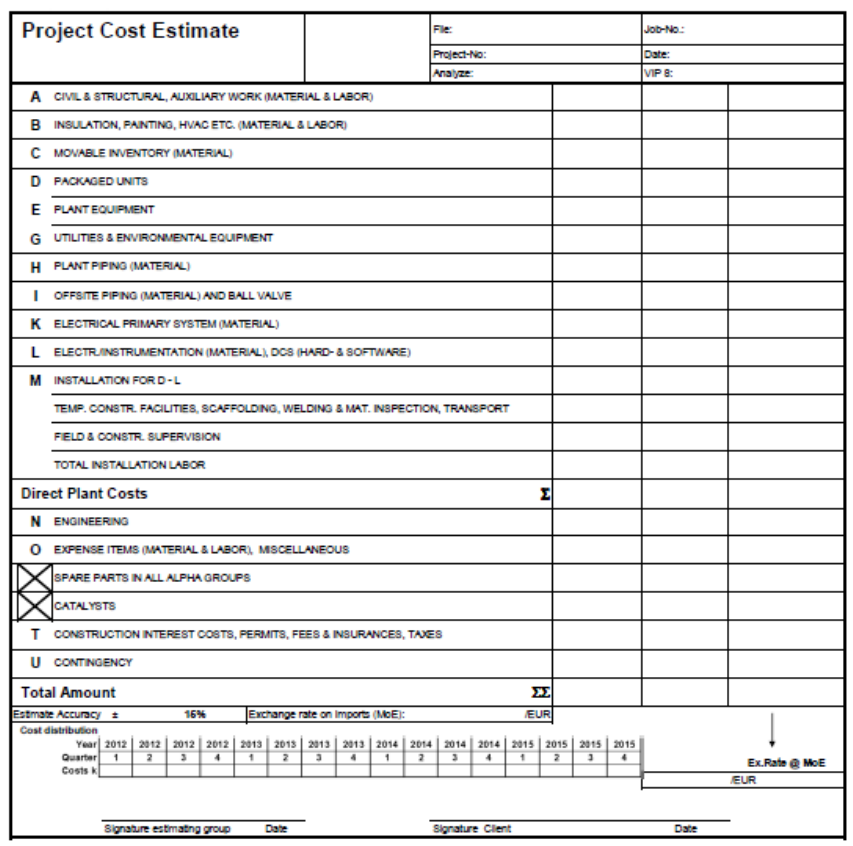

Figure 2: Project cost estimate

To control project cost budget, the template progress report is developed for estimating and comparison between estimated and actual budget for each project as shown in Figure 3.

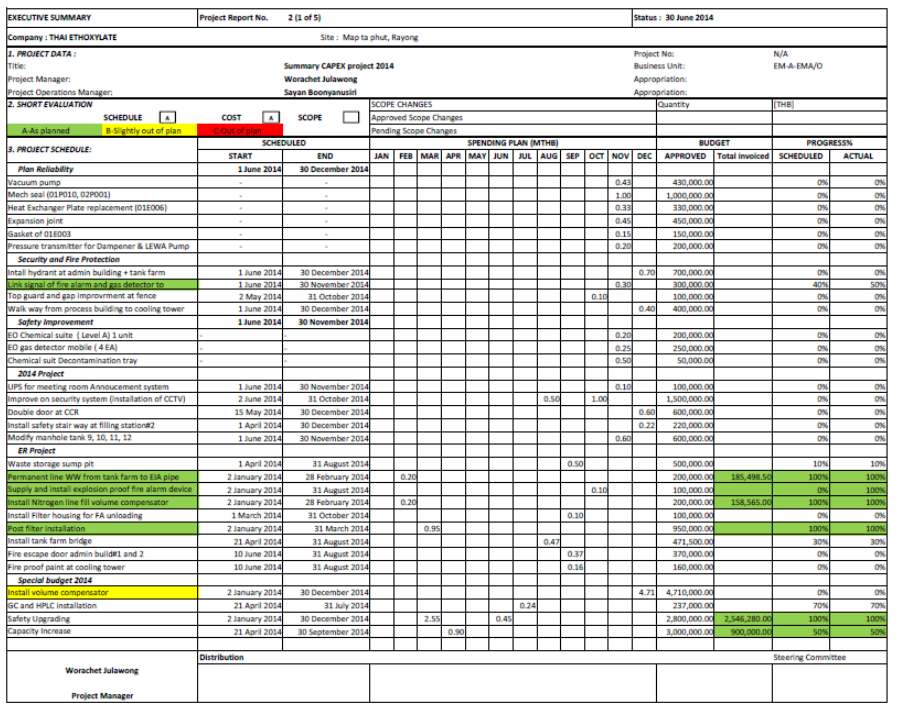

Figure 3: Project cost control and expense

\subsection{Project quality management}

To control project quality to meet with project requirement and specification, the testing and inspection plan is provided with the sampling point or testing step as shown in Figure 4.

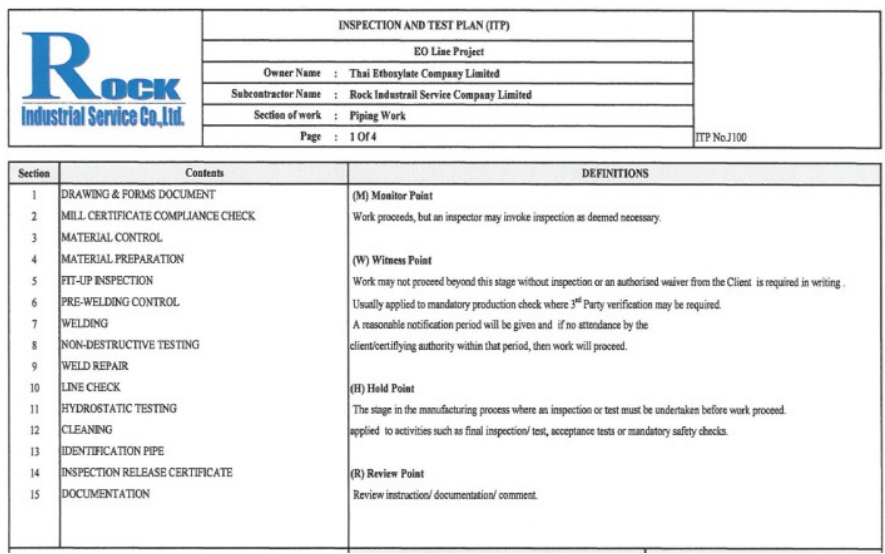

Figure 4: Inspection and test plan

To monitor and record results of the individual activity quality, the project team defines the project specification e.g. piping specification, testing method, platform and equipment support typical structure. The example of inspection report is shown in Figure 5. 


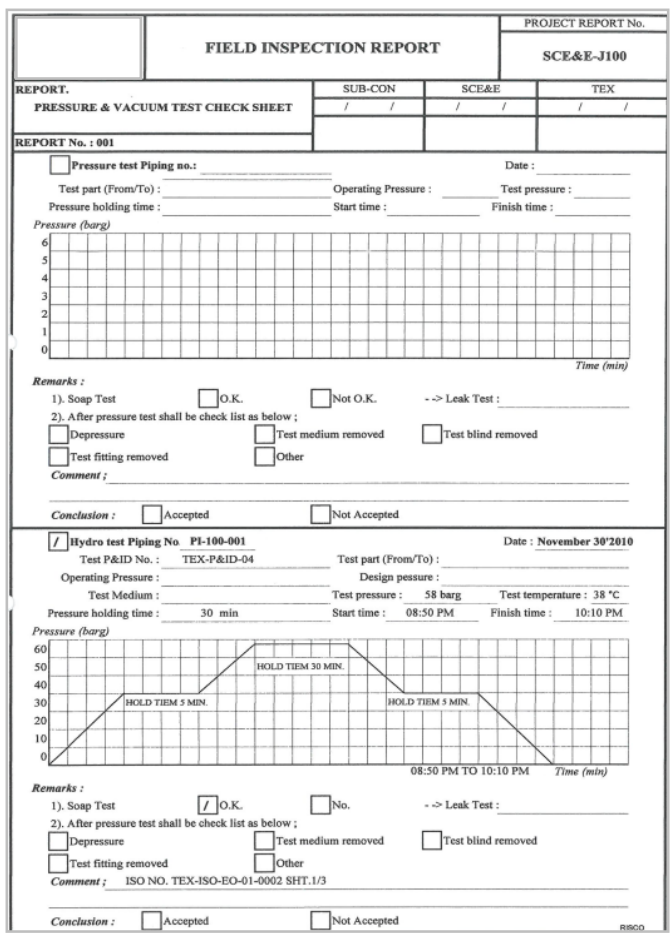

Figure 5: Field inspection report

\subsection{Project risk management}

The case study company project risk evaluation model is shown in Figure 5. Appropriate actions are defined for all activities with high risk to alleviate or negate their impacts as much as possible.

Project risk management models are used for evaluating the opportunity and impact levels shown in Figure 6. The red zone is high risk activity. The engineer tries to reduce risk or make the mitigation plan to reduce the impact of project delay or cost over spending plan.

\begin{tabular}{||c|c|c|c|c|c||}
\hline \multicolumn{6}{|c|}{ Risk Management Matrix } \\
\hline \multirow{2}{*}{ Probability } & $\begin{array}{c}\text { Very Low } \\
(1)\end{array}$ & $\begin{array}{c}\text { Low } \\
(2)\end{array}$ & $\begin{array}{c}\text { Medium } \\
(3)\end{array}$ & $\begin{array}{c}\text { High } \\
(4)\end{array}$ & $\begin{array}{c}\text { Very High } \\
(5)\end{array}$ \\
\hline $\begin{array}{c}\text { Rare } \\
(1)\end{array}$ & 1 & 2 & 3 & 4 & 5 \\
\hline $\begin{array}{c}\text { Unlikely } \\
(2)\end{array}$ & 2 & 4 & 6 & 8 & 10 \\
\hline $\begin{array}{c}\text { Possible } \\
\text { (3) }\end{array}$ & 3 & 6 & 9 & 12 & 15 \\
\hline $\begin{array}{c}\text { Likely } \\
(4)\end{array}$ & 4 & 8 & 12 & 16 & 20 \\
\hline $\begin{array}{c}\text { Almost } \\
\text { Curtain } \\
\text { (5) }\end{array}$ & 5 & 10 & 15 & 20 & 25 \\
\hline \hline
\end{tabular}

Figure 6: Project risk evaluating model
The project control management model and platform shows the status of project completion and in-progress projects which will be successful in 2014 (Figure 7).

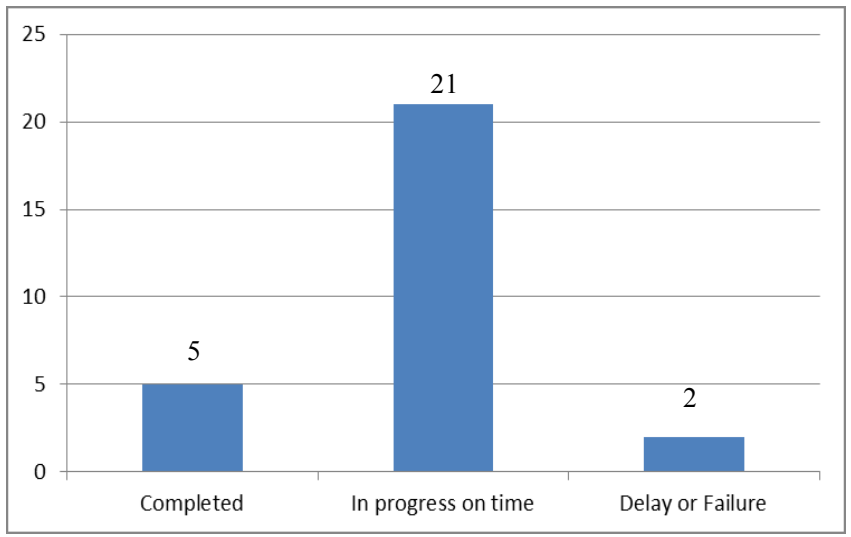

Figure 7: Survey result: Project control management

\section{CONCLUSION}

Different projects have different requirements and specifications. Some projects have constraint in terms of completion time whereas cost constraint could be very important in some projects. In this case study, the concept of PMBOX is employed to manage projects in achieving on-time delivery. It is found that this concept works quite well and the number of the projects completed on time in 2014 is expected to increase to $90 \%$ with acceptable cost. In addition, it can be used as a guideline for the future projects of the company.

\section{REFERENCES}

[1] Madau, R. and Pretorius, L. 2009, Project Control and Risk Management for Project Success: A South African Case Study, PICMET 2009 Proceedings, August 2-6, Portland, Oregon USA (c) 2009 PICMET

[2] Wei, J. 2010, Application of Project Management Techniques in Construction Management. IEEE: P516520.

[3] Danijela, K. and Davorin, V. 2013, Using Microsoft Project for Project Management in Non-Governmental Organisations: MIPRO, Opatija, Croatia

[4] Project Management Institute. 2008, A Guide to the Project Management Body of Knowledge.

[5] Suthas, R. 2013, Project Management: Tools and Techniques, Chulalongkorn University Printing House.

[6] Harold K. 2006, Project Management: A Systems Approach to Planning, Scheduling, and Controlling. 